\title{
A study of factors causing meconium stained amniotic fluid and it's impact on perinatal outcome
}

\author{
CH Prasanna Kumari ${ }^{1{ }^{1 *},}$ A. Ashwini ${ }^{2}$, K. Aparna ${ }^{3}$, N. V. R. Murty ${ }^{4}$ \\ ${ }^{1} \mathrm{DGO}$ DNB, ${ }^{2}$ Consultant, ${ }^{3} \mathrm{HOD},{ }^{4}$ Consultant, Dept. of Obstetrics and Gynecology, St. Theresa's Hospital, Hyderabad, India \\ *Corresponding Author: \\ Email: prasu.ch4@gmail.com
}

\begin{abstract}
Objectives: To identify the risk factors for meconium stained amniotic fluid (MSAF) and it's impact on perinatal outcome. Materials and Methods: This prospective, observational study was conducted in labour room \& operation theatre of St. Theresa's Hospital from May 2015-May 2016. A total of 110 women who were found to have meconium on spontaneous or artificial rupture of membranes were monitored with fetal heart rate abnormalities,5 minute APGAR score and neonatal complications like meconium aspiration syndrome(MAS) as outcome variables.

Results: The results of the study were analysed statistically using Windostat Version 9.2. The incidence of MSAF was $12.01 \%$. Based on this study, it is evident that the incidence of MSAF was more in women with Oligohydramnios, Prolonged pregnancy, Diabetes complicating pregnancy, Hypertensive disorders in pregnancy, Fetal growth restriction and in women with induced labour.

The Chi Square test was applied between Grades of Meconium and APGAR Score. p value $<0.05$ which was statistically significant. Also, the study between Grades of Meconium and Cardiotocograph (CTG) pattern proved to be significant with $p$ value $<0.05$.

Conclusion: MSAF alone is not associated with an adverse neonatal outcome, $78.18 \%$ of abies remained asymptomatic. Increasing grade of meconium is associated with increased adverse outcome. Association of MSAF with abnormal CTG is associated with poor outcome, increased caesarean section rate, increased neonatal complications. The presence of thick meconium is associated with increase in the perinatal morbidity and mortality and hence its presence should not be overlooked.
\end{abstract}

Keywords: MSAF, CTG, APGAR score, Meconium Aspiration Syndrome.

\section{Introduction}

Meconium is the first intestinal secretion from fetus. During intrauterine life normally fetus does not pass meconium. In recent studies the overall frequency of meconium stained amniotic fluid (MSAF) has ranged from 5 to $24.6 \%$ (median 14\%) of all deliveries. ${ }^{1}$ The presence of meconium stained amniotic fluid is a serious sign of foetal compromise, which is associated with an increase in perinatal morbidity, ${ }^{2,3}$ clear amniotic fluid on the other hand is considered reassuring. In earlier days, early amniotomy with active management of labour was done to detect meconium passed during labour. ${ }^{4}$ Amniotomy in labour is also commonly performed to detect meconium where fetal heart rate is unsatisfactory. ${ }^{5}$ If meconium stained amniotic fluid is found, continuous fetal heart rate monitoring is required for foetal well being. ${ }^{6}$

The exact etiology of MSAF remains unclear. Presence of meconium in amniotic fluid is an independent marker of fetal distress .The pathological explanation proposes that fetus passes meconium in response to hypoxia and that meconium therefore signals fetal compromise. ${ }^{7}$ Alternatively, in utero passage of meconium may represent normal gastrointestinal tract maturation under neural control. ${ }^{8}$ Meconium passage could follow vagal stimulation from transient umbilical cord entrapment and resultant increased peristalsis ${ }^{9}$ representing physiological processes. The term "meconium aspiration syndrome
(MAS)" describes neonates born through MSAF, who present with respiratory distress which cannot be otherwise explained. MAS is the most frequent complication diagnosed among infants born through MSAF, with an incidence of about $5 \%$ in these cases. ${ }^{1}$ Meconium stained infants are considered 100 times more likely to develop MAS, compared with infants born through clear amniotic fluid. ${ }^{10}$

The aim of this study was to identify the risk factors for meconium stained amniotic fluid (MSAF) and it's impact on perinatal outcome. Since all fetuses with meconium passage in labour do not have associated maternal risk factors and do not have adverse outcome, careful intrapartum monitoring is required to distinguish those who are destined to develop foetal distress promptly and intervene accordingly to prevent meconium aspiration syndrome and sequelae.

\section{Materials and Methods}

After obtaining ethical clearance and informed written consent this prospective, obseravational study was done from May 2015 to May 2016 in the department of Obstetrics and Gynaecology at St Theresa's hospital, Hyderabad. 110 women who fulfilled the inclusion criteria were enrolled in the study.

Inclusion criteria were gestational age of $>37$ weeks, singleton pregnancy and cephalic presentation with the presence of meconium in amniotic fluid 
following amniotomy or spontaneous rupture of membranes, irrespective of maternal age or parity.

Exclusion criteria were multiple gestation, breech presentation, congenital anomaly of the fetus, chronic renal, pulmonary and cardiac disorders, preterm labour, intrauterine fetal demise, patient refusal.

Patient's detailed history, gestational age, per abdominal examination, per speculum and per vaginal examination, admission tests including intrapartum CTG were recorded. Risk factors like Oligohydramnios, Prolonged and Post term pregnancy, Hypertensive disorders, Diabetes complicating

Grade of the meconium was graded as Grade 1, 2 and 3 depending on its appearance after spontaneous or artificial rupture of the membranes. Grade I is translucent, light green in colour. Grade 2 is opalescent with light green in colour. Grade 3 is thick paste like and dark green in colour. Delivery was expedited when fetal heart rate abnormalities were detected on CTG. pregnancy, Intrauterine growth restriction (IUGR) and Prolonged Premature rupture of membranes (PROM) were noted. Routine hematological and urine examinations were done. Careful monitoring of the progress of labour was done by plotting the parameters on a partogram. Strict monitoring of the fetal heart rate was done by continuous electronic fetal monitoring. The fetal heart rate tracings were classified as reassuring, non reassuring and abnormal according to the National Institute for Clinical Exellence (NICE) guidelines.

Mode of delivery was individualized and was decided only after full trial of labour. Caesarian section was done only if trial of labour was unsuccessful or if there was any other indication for it. The APGAR score at 5 minutes, birth weight, need for NICU admission, presence of meconium aspiration syndrome and birth asphyxia were recorded.

\section{Results}

Comparison of proportions was done using the chi square test. Mean and standard deviations were calculated using standard methodologies. P value of less than 0.05 was considered statistically significant.

During the study period of one year, 110 had meconium stained liquor, giving the incidence of $12.01 \%$. Mean age was $24.16 y$ rs and mean gestational age was 39.236 weeks.

Table 1: Distribution of subjects according to grade of MSAF

\begin{tabular}{|l|c|c|}
\hline Grade of MSAF & No. & Percentage \\
\hline Grade 1 & 21 & $19.09 \%$ \\
\hline Grade 2 & 54 & $49.09 \%$ \\
\hline Grade 3 & 35 & $31.82 \%$ \\
\hline
\end{tabular}

Out of 110 subjects studied, majority of the subjects that is $49.09 \%$ had Grade 2 MSAF, $31.82 \%$ had Grade 3 MSAF and $19.09 \%$ had Grade 1 MSAF.

Table 2: Distribution of subjects according to the risk factors

\begin{tabular}{|l|c|c|}
\hline \multicolumn{1}{|c|}{ Risk factor } & Number & Percentage \\
\hline Oligohydramnios & 37 & $33.63 \%$ \\
\hline Prolonged pregnancy & 24 & $21.81 \%$ \\
\hline Diabetes complicating pregnancy & 22 & $20 \%$ \\
\hline $\begin{array}{l}\text { Prolonged premature rupture of } \\
\text { membranes (prolonged prom) }\end{array}$ & 17 & $15.45 \%$ \\
\hline $\begin{array}{l}\text { Hypertensive disorders in } \\
\text { pregnancy }\end{array}$ & 15 & $13.63 \%$ \\
\hline Hypothyroidism & 8 & $7.27 \%$ \\
\hline Rh negative pregnancy & 8 & $7.27 \%$ \\
\hline Anemia complicating pregnancy & 7 & $6.36 \%$ \\
\hline Teenage pregnancy & 7 & $6.36 \%$ \\
\hline Intra uterine growth restriction (iugr) & 4 & $3.63 \%$ \\
\hline Placenta previa & 2 & $1.81 \%$ \\
\hline Viral hepatitis & 1 & $0.91 \%$ \\
\hline Asthma & 1 & $0.91 \%$ \\
\hline Thrombocytopenia & 1 & $0.91 \%$ \\
\hline Post term pregnancy & 1 & $0.91 \%$ \\
\hline Multiple risk factors & 39 & $35.45 \%$ \\
\hline No risk factor & 12 & $10.90 \%$ \\
\hline
\end{tabular}

Out of 110 subjects studied $35.45 \%$ had multiple risk factors and $10.9 \%$ had no risk factors. 
Table 3: Correlation between CTG and grade of MSAF

\begin{tabular}{|l|c|c|c|}
\hline CTG & Grade 1 MSAF & Grade 2 MSAF & Grade 3 MSAF \\
\hline Reactive & $21(100 \%)$ & $22(40.74 \%)$ & $1(2.86 \%)$ \\
\hline Non reactive & 0 & $32(59.26 \%)$ & $34(97.14 \%)$ \\
\hline Total & $21(100 \%)$ & $54(100 \%)$ & $35(100 \%)$ \\
\hline
\end{tabular}

The correlation between CTG and Grade of MSAF is statistically very highly significant.

$\mathrm{P}$ value is $<0.000$.

Table 4: Correlation between grade of MSAF and mode of delivery

\begin{tabular}{|l|c|c|c|}
\hline Mode of Delivery & Grade 1 MSAF & Grade 2 MSAF & Grade 3 MSAF \\
\hline NVD & $17(80.95 \%)$ & $10(18.52 \%)$ & $4(11.43 \%)$ \\
\hline Forceps Delivery & $1(4.76 \%)$ & $1(1.85 \%)$ & $4(11.43 \%)$ \\
\hline LSCS & $3(14.29 \%)$ & $43(79.63 \%)$ & $27(77.14 \%)$ \\
\hline TOTAL & $21(100 \%)$ & $54(100 \%)$ & $35(100 \%)$ \\
\hline
\end{tabular}

This correlation is statistically very highly significant, $\mathrm{P}$ value is $<0.0001$.

Table 5: Corelation between grade of MSAF and APGAR at 5 minutes

\begin{tabular}{|l|c|c|c|}
\hline $\begin{array}{l}\text { APGAR at 5 } \\
\text { minutes }\end{array}$ & Grade 1 MSAF & Grade 2 MSAF & Grade 3 MSAF \\
\hline$\leq 7$ & 0 & $17(31.48 \%)$ & $35(100 \%)$ \\
\hline$>7$ & $21(100 \%)$ & $37(68.52 \%)$ & 0 \\
\hline Total & $21(100 \%)$ & $54(100 \%)$ & $35(100 \%)$ \\
\hline
\end{tabular}

This correlation is statistically very highly significant, $\mathrm{P}$ value is $<0.000$.

Table 6: Correlation between grade of MSAF and neonatal outcome

\begin{tabular}{|l|c|c|c|}
\hline $\begin{array}{l}\text { Neonatal } \\
\text { Outcome }\end{array}$ & Grade 1 MSAF & Grade 2 MSAF & Grade 3 MSAF \\
\hline Asymptomatic & $21(100 \%)$ & $49(90.74 \%)$ & $16(45.72 \%)$ \\
\hline NICU Admission & 0 & $5(9.26 \%)$ & $14(40 \%)$ \\
\hline MAS & 0 & 0 & $5(14.28 \%)$ \\
\hline Total & $21(100 \%)$ & $54(100 \%)$ & $35(100 \%)$ \\
\hline
\end{tabular}

In our study, Grade 1 MSAF was not associated with respiratory distress or NICU admission. NICU admissions were more with Grade $3 \mathrm{MSAF}$ than Grade $2 \mathrm{MSAF}$, which indictes the impact of grade or thickness of the meconium on neonatal outcome.

\section{Discussion}

During our study period of one year, a total of 1057 women were delivered at term. Out of 1057 women, 127 had MSAF, with an incidence of $12.01 \%$, which is similar to the study done by and Naveen $\mathrm{S}$ et al. ${ }^{11}$

In our study, Out of 110 subjects studied, 37 subjects had Oligohydramnios, 24 were Post dated pregnancies, 22 were Diabetes complicating pregnancies, 17 had Prolonged PROM, 15 had hypertensive disorders, 8 had Hypothyroidism, 8 were Rh negative pregnancies, 7 were Teenage pregnancies, 7 had Anemia, 4 had IUGR, 2 had Placenta previa, 1 had Viral hepatitis, 1 had Asthma, 1 had Thrombocytopenia, 1 was Post term pregnancy. 39 had multiple risk factors and 12 had no risk factors. In the study done by Meena priyadarshini et al, ${ }^{12}$ out of 250 subjects who had MSAF, 82 were post dated pregnancies, 12 subjects had PIH, 12 had Rh isoimmunisation, 9 had Oligohydramnios, 8 had GDM,
5 had Heart disease, 5 were of Higher Maternal Age, 4 had Chronic Respiratory disease, 3 were Teenage pregnancies, 3 had Cholestasis of pregnancy, 9 had PROM, 8 had IUGR, 3 had Prolonged labour, 1 had Circumvallate Placenta, 1 had Ileal Atresia, 1 had Premature atrial contraction of fetus.

In our study, the correlation between CTG and MSAF was statistically significant. In this study, majority of the subjects with Grade 3 MSAF had Non reassuring CTG compared to Grade 1 \&2 MSAF, which is similar to the studies by Nirmala et $\mathrm{al}^{13}$ and Meena priyadarshini et al. ${ }^{12}$

In our study, rate of LSCS was more in Grade $2 \& 3$ MSAF (79.63\% and $77.14 \%$ respectively) compared to Grade 1 MSAF(14.29\%). Similarily LSCS rate was $42 \%$ in the study of Patil et al, ${ }^{14} 62.5 \%$ in study of Espinheira 15, 49.1\% in study of Naveen $\mathrm{S}$ et al. ${ }^{11}$

In our study, APGAR score $\leq 7$ was more in Grade 3 MSAF compared to Grade $1 \& 2$, which 
is similar to the studies of Meena priyadarshini et $\mathrm{al}^{12}$ and Nirmala et al. ${ }^{13}$

In our study, $78.18 \%$ babies were asymptomatic, which is comparable to study done by Mundhra et al. NICU admission was required for $21.81 \%$ of babies, which is similar to studies done by Mundhra $\mathrm{R}$ et al, ${ }^{16}$ Patil et al ${ }^{14}$ and Mahapatro et al. ${ }^{17}$ MAS was seen in 5 (4.54\%) babies with Grade 3 MSAF, among which 2 were referred to higher center for ventilatory support and 3 were kept in NICU for one week in view of severe respiratory distress. No babies with Grade 1 MSAF had respiratory distress or MAS. This shows the correlation between consistency of meconium and neonatal outcome.

\section{Conclusion}

From this study it is evident that MSAF is commonly observed during labour. Majority of babies who were born with MSAF were asymptomatic and routine care was adequate for them. Increasing Grade of meconium is associated with adverse outcome. Presence of both MSAF and abnormal CTG is associated with poor outcome, increased caesarean section rate, increased neonatal complications. Meconium aspiration syndrome is a significant cause of perinatal morbidity and mortality, which can be reduced by early detection of meconium, prompt delivery and neonatal resuscitation.

\section{References}

1. Cleary GM, Wiswell T E. Meconium-stained amniotic fluid and the meconium aspiration syndrome, an update. Pediatr Clin North Am 1998;45(5):11-29.

2. Berkus MD, Langer O, Samuelloff A, Xenakis EM, Field NT, Ridgeway LE.Meconium stained amniotic fluid: increased risk for adverse outcome. Obstet Gynecol 1994;84:115-20.

3. Nathan L, Leveno KJ, Camody TJ 3rd, Kelly MA, Sherman ML. Meconium: a 1990's perspective as an old obstetric hazard. Obstet Gynecol 1994;83:329-32.

4. Clinical Effectiveness Support Unit. The use of electronic fetal monitoring.Evidence-based clinical guideline no. 8 . London: RCOG Press, 2001. (Online) Cited 2003 May 19. Available from URL: $\mathrm{kl}=\mathrm{lko} 0$. uk/pdf/efmguidelinercog.pdf.

5. Goffinet F, Fraser W, Marcoux S, Breart G, Moutquin JM, Daris M. Early amniotomy increases the frequency of fetal heart rate abnormalities. Amniotomy Study Group. Br J Obstet Gynaecol 1997;104:548-53.

6. Miller FC, Sacks DA, Yeh SY, Paul RH, Schirfin BS, Martin CB Jr. Significance of meconium staining during labor. Am J Obstet Gynecol 1975;122:573-80.

7. Walker J: foetal anoxia. J Obstet Gynaecol Br Emp. 1953;61:162.

8. Mathews TG, Warshaw JB: Relevance of the gestational age distribution of meconium passage in utero. Pediatrics 1979;64:30.

9. Hon EH, Bradfield AM, Hess OW: The electronic evaluation of fetal heart rate. Am J Obstet Gynecol 1961;82:291.

10. Fleischer A, Anyaegbunam A, Guidetti D, Randolph G, Merkatz IR. A persistent clinical problem: profile of the term infant with significant respiratory complications. Obstet Gynecol 1992;79:185-90.

11. Naveen S,Kumar SV,Ritu S,Kushia P . Predictors of meconium stained amniotic fluid: a possible strategy to reduce neonatal morbidity \& mortality.J obstet Gynecol India. Nov/Dec 2006;56 (6):514-7.

12. Meena Priyadharshini V, Panicker S . Meconium Stained Liquor and Its Fetal Outcome - Retrospective study. IOSR Journal of Dental and Medical Sciences (IOSRJDMS) e-ISSN: 2279-0853, p-ISSN: 2279-0861. Volume 6, Issue 2 (Mar.- Apr. 2013), PP 27-31.

13. Nirmala D, Paul A, Urmila D, Anjali. Meconium staining of amniotic fluid-A poor indicator of foetal compromise. J k science . Oct- Dec 2010; vol 12 no.4:184-6.

14. Kamal P, Swamy MK, Samatha K. A one year cross sectional study of management practices of meconium stained amniotic fluid and perinatal outcome. J Obstet Gynecol India. March/April 2006; Vol. 56, No. 2: Pg 12830.

15. Espinheira MC, Grilo M, Rocha G, Guedes B, Guimarães $\mathrm{H}$. Meconium aspiration syndrome - the experience of a tertiary centre. Rev portal pneumol 2011 mar - apr ;17(2):71-6. PMID:21477569.

16. Mundhra R, Agarwal M. Fetal outcome in meconium stained deliveries. Journal of Clinical and Diagnostic Research. 2013 Dec; Vol-7(12): 2874-2876. PMCID: PMC3919335.PMID:24551662.

17. Mahapatro AK, Ghose S. Obstetrics outcome at term in meconium stained amniotic fluid - a retrospective study. Int J Pharm Bio Sci. 2014 April;5 (2):(B) 866-71. 